\title{
Marketing through a joint commercial product portfolio: Business drivers, benefits, and challenges
}

\begin{abstract}
Purpose - This study aims to improve understanding of companies' motives and concerns in relation to cooperation through a joint commercial product portfolio.
\end{abstract}

Design/methodology/approach - The qualitative research method was used to study 16 companies based on two case projects.

Findings - The possible business drivers, targeted benefits, and perceived challenges of small and medium-sized enterprises (SMEs) in relation to cooperation through a joint commercial product portfolio were identified. The companies seem to be motivated by and concerned about similar issues that also apply to other forms of co-marketing.

Research limitations/implications - The study consisted of two case projects in the same country and, thus, share fairly similar business environments and cultures. Therefore, the same results may not be obtained for a study that is conducted in a different location.

Practical implications - Managers of SMEs can benefit from the results of this study by improving their understanding of co-marketing opportunities through the creation of a joint commercial product portfolio with suitable companies. In addition, the results provide managers with insights into the challenges that should be considered when planning marketing cooperation.

Originality/value - The study provides new perspectives on the existing co-marketing literature by discussing the creation of a joint commercial product portfolio as a vehicle to support companies' business objectives. The study contributes to the increasing business-to-business co-marketing literature by presenting the business drivers, targeted benefits, and perceived challenges related to SMEs cooperation through a joint commercial product portfolio. 


\section{INTRODUCTION}

A company that buys products or services to support its own operations may benefit if a wider variety of these is offered by a single source (Swift, 1995; Costantino and Pellegrino, 2010) as opposed to many smaller individual suppliers. Additionally, from the perspective of smaller suppliers, improving the visibility of their products or services among existing or potential customer companies might be beneficial. Buying from a single source is seen as beneficial if the buying company's offering is specialised (Segal, 1989). However, few studies have considered several smaller suppliers marketing their products together by forming a virtual offering that would appear as one large offering and source of supply to the companies' customers.

Cooperative marketing activities have gained increasing interest in recent decades (Agostini and Nosella, 2017). However, while quantitative methodologies have been used for a fair share of earlier co-marketing research (Grieco and Iasevoli, 2017), a paucity seems to exist in relation to qualitative research on co-marketing in the cases of cooperation between multi-partner small and medium-sized enterprises (SMEs) (Agostini and Nosella, 2017). In multi-partner co-marketing, multiple companies within the value chain cooperate by mutual agreement (Lavie et al., 2007). While most of the earlier research has focused on business-to-consumer (B2C) co-marketing, the current literature on business-to-business (B2B) co-marketing has, for the most part, addressed component branding (Kalafatis et al., 2012), thus neglecting the other forms of co-marketing, such as marketing through a joint commercial product portfolio. This is a form of horizontal cooperation in which multiple companies market their products together as one offering. In the joint commercial product portfolio, cooperation does not cover the sharing of the production responsibilities, which means that each company produces only its own part of the joint offering. The joint commercial product portfolio is constructed and developed in a mutual understanding between the companies. Hence, the joint portfolio is not just a traditional product catalogue consisting of separate company-specific offerings but a well-designed offering consisting of appropriate product families that may cross company borders.

The present study seeks to fill the gap in co-marketing research by examining the business drivers, targeted benefits and perceived challenges of cooperation by multiple B2B SMEs 
through a joint commercial product portfolio. More specifically, the study aims to reveal companies' motives and concerns in relation to this type of cooperation.

The study has two research questions:

1. What are the business drivers and targeted benefits of cooperation through a joint commercial product portfolio?

2. What are the perceived challenges of cooperation through a joint commercial product portfolio?

After reviewing the current literature on co-marketing, this study approaches the research questions by means of unstructured interviews with B2B SMEs aiming for commercial cooperation. The collected data are analysed, and business drivers, targeted benefits, and challenges are synthesised. 


\section{LITERATURE REVIEW}

Academic and managerial interest in interorganisational marketing relationships has increased in recent decades (Agostini and Nosella, 2017). Co-marketing as a concept is difficult to define, as researchers have different views and it consists of several subconcepts (Grieco and Iasevoli, 2017). These sub-concepts include brand alliances, comarketing alliances, and promotional alliances (Bucklin and Sengupta, 1993; Park et al., 1996; Robson and Dunk, 1999; Gammoh et al., 2006; Augustine and Cooper, 2009; Karray and Sigué, 2015). Cooperation may also be realised through joint ventures (Gou et al., 2014). It might be the choosing of the alliance partners that determines the success of the alliance (Ahn et al., 2009), but an alliance can be formed among carefully chosen partners or can be open to everyone (Sengupta, 1998).

Co-marketing can be related to customer service, marketing and promotion, and distribution (Das et al., 2003). It may take place in a horizontal or vertical direction (Felzensztein et al., 2012). Horizontal cooperation in this context occurs between companies at the same level of the supply chain, while vertical cooperation occurs between companies at different levels of the supply chain (Gou et al., 2014). The forms of co-marketing include joint promotion (products with different brands promoted as complementary), co-branding (using two brands in single product's name), ingredient/component branding (using a branded component in the product's technical structure), dual branding (selling multiple products in the same location), licensing/renting a brand, product bundling (selling multiple products as a package for one price), or selling multiple brands in the same product category (Rao and Ruekert, 1994; Levin et al., 1996; Park et al., 1996; Venkatesh and Mahajan, 1997; Robson and Dunk, 1999; Voss and Tansuhaj, 1999; Teng and Das, 2008; Ahn et al., 2009; Karray and Sigué, 2016). Other practical examples of co-marketing include having a shared exhibition stand, and organising joint events, roadshows, or press releases (Törmälä and Saraniemi, 2018). In line with Grieco and Iasevoli (2017), co-marketing is used in this study as an umbrella term for all the arrangements related to cooperative marketing. 


\section{Business drivers and the benefits of co-marketing}

The factors driving companies towards co-marketing can be found within both the environment and the companies themselves. An example of an environmental driver is competition. Due to intense competition, companies seek new ways to sustain their business (Robson and Dunk, 1999). Conversely, the companies may seek cooperative marketing opportunities due to factors that characterise the firms. For example, small companies may have insufficient resources due to their sizes, driving them to find solutions through cooperation (Chen and Huang, 2004). The companies' positive attitude towards cooperation may also act as a driver (Robson and Dunk, 1999; Chen and Huang, 2004). Previous positive experiences with co-marketing and a supportive attitude on the part of management play an important role in this regard (Gammoh and Voss, 2013).

Companies enter into co-marketing as they assume that they will derive benefits that they would not get by themselves (Yi et al., 2010). In an ideal case, co-marketing can lead to relational rent (Ferdinand and Killa, 2018) that is "a supernormal profit jointly generated in an exchange relationship that cannot be generated by either firm in isolation and can only be created through the joint idiosyncratic contributions of the specific alliance partners" (Dyer and Singh, 1998, p. 662). Additionally, trust plays a role in building relationships between companies and may take some time to establish (Fink and Kessler, 2010). In regard to co-marketing, Karray and Sigué (2015) suggest that increasing sales and profitability are be the fundamental benefits for which companies strive. These can be achieved in many ways, and different specific benefits may be targeted. Cost savings can be gained due to the elimination of duplicate activities, synergy benefits, and economies of scale (Robson and Dunk, 1999). Marketing efficiency can also be improved as the rate of return on marketing investments increases (Chen and Huang 2004).

Co-marketing is used to gain access to assets that the company does not yet have but its partners do, such as products, technologies, materials, and expertise (Bucklin and Sengupta, 1993; Rao and Ruekert, 1994; Robson and Dunk, 1999; Chen and Huang, 2004). These gains are not limited solely to existing assets, as the company can foster its partner's development efforts by supporting the partner's business growth (Ghosh and John, 2009). Through cooperation, the company can provide a larger product offering and serve a wider range of customer needs (Robson and Dunk, 1999; Gilmore et al., 2001). 
In addition, the company can benefit in the form of learning or by accruing intellectual capital (Varadarajan and Cunningham, 1995; Das et al., 2003; Kalafatis et al., 2012).

One benefit of co-marketing relates to the company's brand. Cooperative marketing can be used as a vehicle to enhance brand image (Rao and Ruekert, 1994; Park et al., 1996; Voss and Tansuhaj, 1999; Voss and Gammoh, 2004; Gammoh et al., 2010; Mishra et al., 2017). The company's brand image can be affected by the entire network in which it is operating (Mäläskä et al., 2011; Törmälä and Saraniemi, 2018). In co-marketing, a weaker brand can gain credibility when presented together with a stronger, more reputable one (Bengtsson and Servais, 2005). The better-known brand also affects the impression of the other brand's quality, although this effect might be negative (Kalafatis et al, 2014). The effect that different brands have on each other has also been studied in the case of services (Morgan et al., 2007; Helm and Özergin, 2015). By marketing their products jointly, companies can create awareness of the compatibility between their offerings (Bengtsson and Servais, 2005). They can also communicate to customers about the benefits of compatibility, thus strengthening the brands (Lavie et al., 2007; Ahn et al., 2009). In addition, co-marketing can be used to create awareness of the brand (Augustine and Cooper, 2009).

The expansion to new markets or industries and the increase or sustenance of the existing market share may also be targeted by co-marketing (Rao and Ruekert, 1994; Varadarajan and Cunningham, 1995; Robson and Dunk, 1999; Voss and Tansuhaj, 1999; Chen and Huang, 2004). For example, the company may leverage its partners' existing sales channels (Robson and Dunk, 1999). Partnering with a domestic company may facilitate a foreign company's market entry (Voss and Tansuhaj, 1999), as the customer does not associate much risk with the foreign brand when cooperation exists with a local company (Mohan et al., 2018). However, not all companies wish to go abroad, due to issues such as differences in culture, government, legislation, language, or logistics (Neupert et al., 2006; Ratajczak-Mrozek et al., 2019). Especially for smaller companies, managing international relationships is more challenging than managing domestic ones (RatajczakMrozek et al., 2019). Co-marketing can shape the industry structure, for example, by developing and promoting a certain technology or standard (Lavie et al., 2007) and preventing competition by creating entry barriers (Varadarajan and Cunningham, 1995). For example, a component supplier can reduce the risk of competition by entering into a component branding agreement with the manufacturer while the manufacturer obtains 
lower prices in return (Erevelles et al., 2008). Through cooperation, companies may want to keep customers' orders in the local area, thereby preventing their loss to foreign competitors (Gilmore et al., 2001). Cooperation by local companies seems to yield more benefits to smaller, less export-intensive companies (Brown et al., 2010).

\section{The challenges of co-marketing}

Despite the various benefits that co-marketing can yield, challenges and risks exist. In fact, according to Day (1995), up to $70 \%$ of marketing alliances have not been successful.

Challenges in co-marketing may occur due to the composition of the alliance. If the alliance partners neither have nor show long-term commitment to the alliance, they may be unable to overcome problems (Day, 1995). A risk of opportunistic behaviour also exists if there is no trust between the partners (Bucklin and Sengupta, 1993). Their different objectives, roles, perceptions, cultures, and decision-making styles are also apt to cause problems (Day, 1995; Voss et al., 2006; Yi et al., 2010). Trust and cultural sensitivity are determinants of successful information exchange, which, in turn, affects the performance of the marketing alliance (Voss et al., 2006). Bucklin and Sengupta (1993) found that an imbalance of power and managerial resources between the partners might also hinder the effectiveness of co-marketing. They proposed that contracts could reduce the imbalance. However, contracts themselves may cause challenges as the inability to adapt to changes is a threat to the cooperation's success (Day, 1995). The contracts might make the adaptation difficult (Bucklin and Sengupta, 1993). In addition, long contracts may create an issue if a company wants to leave the cooperation for any reason (Rao and Ruekert, 1994).

Challenges and risks can also relate to the outputs of the cooperation. In co-marketing, it is difficult to define which aspects of success can be attributed to which partner (Das et al., 2003). Finding suitable compensation for intangible resources, such as reputation and brand image, may turn out to be difficult (Teng and Das, 2008). Companies with weak brands seem to benefit more from cooperation than their partners that have strong brands (Kalafatis et al., 2012; Helm and Özergin, 2015). Therefore, a risk in co-marketing is the unequal distribution of benefits. Negative spillover effects may occur as the demand increases for one partner but decreases for the other (Karray and Sigué, 2016). In addition, the intellectual capital that is created may be exploited unequally (Das et al., 2003). 
Marketing cooperation may be created to add brand value by linking one brand to another (Rich, 2003); however, success may be limited if the customers do not view the partners' products or brands as compatible (Ahn et al., 2009). Co-marketing can also have negative effects on the company's brand in cases in which the customers' quality expectations are not fulfilled. The issue here is that a negative perception of one partner's brand may have an unfavourable effect on the other partner's brand as well (Rao and Ruekert, 1994). Park et al. (1996) indeed describe co-marketing as the ultimate form of cooperation between companies as they put their reputations on the line. In addition, the monitoring of these negative spillover effects creates additional costs (Ghosh and John, 2009). 


\section{RESEARCH PROCESS AND METHODOLOGY}

\subsection{The research process}

An inductive qualitative research method was used in this study. Unstructured interviews were conducted at multiple companies that were the subjects of two case projects. Unstructured interviews provide a way to gain an in-depth understanding of the studied phenomenon and reveal its unexpected aspects (Zhang and Wildemuth, 2017). The interviewees have the opportunity to focus on the topics that are most relevant to them (Corbin and Morse, 2003). This method was chosen to enable a deeper understanding of the topic at the company level without guiding the interviewees' answers and instead allowing them to reveal their own thoughts. The current research was carried out as illustrated in Figure 1.

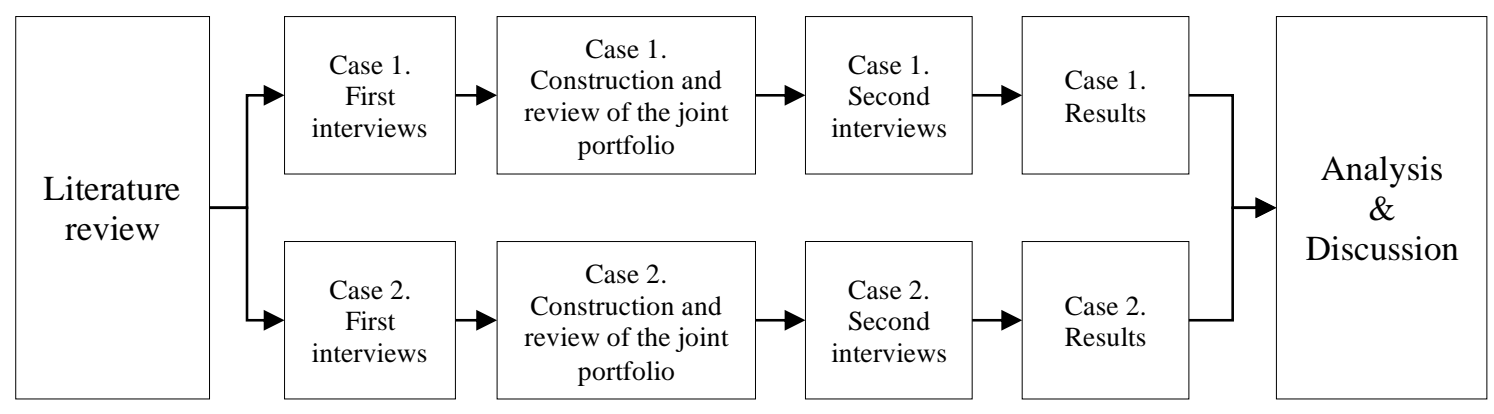

Figure 1. The research process.

The literature related to co-marketing was reviewed to reveal the earlier research that was conducted on the topic. The literature review formed the basis of the research. First, the case projects were created, and the companies were selected. The companies had to fit the European Commission's definition of an SME. The SMEs in Case 1 were selected based on the researchers' access to them due to previous research projects in which the companies had shown an interest in cooperating commercially. To be selected for the study, the companies had to deliver solutions for large steelmakers' process development, quality inspection, or material/energy efficiency improvement. Case 1 provided a fruitful research environment, as the steel industry has faced turbulence due to overcapacity, price competition, and increasing environmental requirements, thereby creating a need to develop new ways of doing business. The SMEs in Case 2 were selected by going through 
the company database of an organisation that promotes local business life. The criteria for selection for Case 2 were that the companies had to provide operations services, which were defined as services for the supply, manufacturing, testing, and logistics of physical products, as well as related product development services. In both cases, the companies were asked to participate in the study. Regarding Case 1, all seven companies that were contacted participated. In regard to Case 2, 32 companies were contacted, of which 9 participated.

The interviews were conducted in a similar fashion for both cases. The company representatives were first interviewed when describing the companies' current independent commercial product portfolios. The descriptions were created by using a common product structure. The commercial product portfolio represents those items in the product structure that can be sold, delivered, and invoiced-that is, the product offering (Tolonen et al., 2014; Harkonen et al., 2017). Based on the independent product portfolios, a joint commercial product portfolio was constructed by reorganising the independent offerings into logical sub-portfolios according to their complementarities. The companies were interviewed for a second time after the joint commercial product portfolio was reviewed with the companies. The second interview provided an opportunity to elicit new thoughts if the interviewees had any. Some interviewees were unable to participate in the second round of interviews due to scheduling issues. During both interviews, the interviewees were asked to describe the business drivers that push their companies towards commercial cooperation through a joint commercial product portfolio. In addition, they were asked to describe the benefits they target and any fears, concerns, or challenges that might discourage the companies from cooperating. Interviewees that were working in the same company did not have any conflicting opinions. The second interviews did not override the results of the first interviews but supported them and, in some cases, provided new insights.

Content analysis was carried out on the data that were gathered from the interviews. There is no single method of carrying out content analysis, but it usually consists of data collection, coding, analysis of content, and interpretation of results (Duriau et al., 2007). It enables the analysis of large amounts of data from different sources, based on which conclusions are made (Elo and Kyngäs, 2008). In this study, the two cases were analysed separately. Transcripts of the interviews were read through carefully to obtain an overall picture and create an initial understanding of the studied cases. During the reading, notes 
were written to outline any ideas. The transcripts were reread multiple times while extracting the interviewees' comments that were seen relevant to the objectives of the study. The comments were divided into coded categories, which were guided by the research questions. The categories were business drivers, targeted benefits, and perceived challenges. In the next stage, the codes within the business drivers' group were combined into sub-categories according to their recurrence and similarities. Initial descriptive names were given to the sub-categories. Next, the codes within the benefits category were further categorised according to the business-driver sub-categories. The transcripts were reviewed simultaneously to ensure that the benefits were related to the correct business drivers. The codes within the perceived challenges category were combined into subcategories according to their recurrence and similarities. After analysing both case projects independently, the results and categorisations were compared to arrive at the findings. The categorisations were fine-tuned, and final names were given to the subcategories. All the results were reviewed in parallel with the original transcripts to ensure that the coding and categorisation matched. No codes omitted from the categorisation.

\subsection{Case projects}

\section{Case Project 1}

In Case Project 1, seven closely located SME-sized companies in Finland that are willing to market their products through a joint commercial product portfolio as a recognisable cluster but wish to maintain their current brands are analysed. The organisational form of the cooperation (e.g. joint sales venture or alliance) is not discussed. Currently, the companies provide their products to the same steel industry manufacturers. The companies' offerings include physical products and services that aim to improve their customers' manufacturing operations. An example of the joint portfolio in this project is that the companies would offer a wide selection of specialised quality inspection devices covering the whole steelmaking process together, compared to every company offering single devices here and there individually. The companies are not competitors, and have already conducted some degree of cooperation in R\&D. However, none of the companies have conducted any marketing cooperation with each other or with any other. The company information can be found in Table 1 .

Table 1. Case Project 1 companies 


\section{Case Project 2}

In Case Project 2, 9 closely located SME-sized companies in Finland who are willing to market their products through a joint commercial product portfolio as independent companies with their own brands are analysed. As in Case Project 1, no stand has been taken on the organisational form of the cooperation. The companies currently provide operations services to various customers and industries. An example of the joint portfolio in this project is that the companies' customers, product businesses, could build the supply chain for their products by searching suitable suppliers that are specialised in specific types of products (e.g. electronics, metal products). Some of the companies are competitors. None of the companies have conducted any cooperative marketing activities with each other or with any other companies. However, buyer-supplier relationships exist between some of them. The company information can be found in Table 2.

Table 2. Case Project 2 companies 


\section{RESULTS}

\subsection{Case Project 1}

\section{Business drivers and targeted benefits}

In Case Project 1, three business drivers to cooperate through a joint commercial product portfolio were identified: need for sales and business growth, customer orientation, and company's drive for cooperation. The targeted benefits emerge from these drivers.

For small start-ups, increasing sales and extending the customer base were seen as important factors for success. However, due to the low number of previous deliveries and references, such companies may lack visibility and credibility (brand awareness and reputation) in the eyes of potential customers and may, thus, be dependent on a few existing customers. The companies wanted to solve these challenges by appearing stronger in the marketplace together and being seen as part of a bigger entity. According to one CEO, "The cooperation enables our company to get its foot in the doors of large factories". By utilising each other's existing customer bases and sales and marketing channels, the companies were expecting to get new customers and reach larger markets. This way, they hoped to build awareness of their company brands. One interviewee also mentioned that cooperation could also be used to build brand awareness of a specific product. In some cases, increasing sales and extending the customer base may necessitate global presence despite scarce resources. Therefore, it is important to choose the right channels carefully and avoid creating unnecessary fixed costs and investments. By marketing their products together, the companies could cover larger markets with minimum investments.

Conversely, the companies hope to serve their customers better. They want to provide higher value to their customers by offering wider and more extensive solutions to fulfil the customers' needs. The overall solution would be more valuable to the customers than the sum of its parts has been previously. The companies see that their customers would benefit from lower procurement costs as more solutions could be acquired through one channel. In addition, customer-supplier communication is expected to improve, thereby enabling transparent and rapid value-creating development activities with the customers. 
The companies' cultures are also cooperation-oriented. They see cooperation as more of an opportunity than a threat. By creating the joint commercial product portfolio, they see the potential for better understanding of each other's product offerings as a whole. Based on this, they expect to derive benefits in terms of the intensification of innovation and resource usage as they can utilise each other's R\&D and marketing capabilities and learn from each other.

\section{Perceived challenges}

In addition to the business drivers and targeted benefits, the interviewees indicated some challenges that were perceived by the companies. In regard to the entire commercial cooperation, embarking on the joint commercial product portfolio at once was seen to involve a high risk. Thus, cooperation is seen as better approached carefully, making small steps.

The different starting points and expectations of the companies were seen as challenges. The interviewees were worried that differing interests could cause problems when developing the cooperation further. This concern is not groundless; for instance, two of the companies have sales turnovers of 5 to 10 million euros, while the remaining companies have sales turnovers of less than 100,000 to 1 million euros. The concern here was that the companies with differing interests might try to develop cooperation opportunistically. It was unclear how this kind of cooperation could be managed to ensure its impartial development and execution. None of the companies were willing to take charge of the execution, nor did they necessarily have any resources to invest in the cooperation. One interviewee suggested that an outsider organisation should take the responsibility for coordination and promotion. However, some challenges were seen to relate to this kind of solution as well. The outsider organisation would focus on promoting and selling products that yield the highest revenues and profits for itself. Therefore, the companies participating in the cooperation would not benefit relatively the same. As one CEO expressed the concern: "an existing market can turn out to be just an illusion even after several years". Payment mechanisms, and metrics for evaluating the benefits yielding from the cooperation, should be developed carefully.

In addition, the challenge of understanding the value of the joint commercial product portfolio and the other companies' products was raised as a potential challenge. Although clear benefits were identified, some of the companies did not view cooperation through 
the joint commercial product portfolio as very valuable. One of the interviewees felt that marketing the overall areas of expertise rather than the joint product portfolio would be preferable to conducting commercial cooperation. Additionally, one CEO did not view his company's products as fitting in with those of other companies. In this particular case, however, the other interviewees did see the fit. In addition, the lack of understanding of each other's products would create challenges in marketing and selling. Marketing personnel were seen to have the need to understand all companies' products to enable them to effectively market the joint product portfolio. One CEO proposed a solution to the marketing of the common offering:

On the other hand, it [the cooperation] could be conducted so that the companies' representatives would visit the potential customers together and jointly discuss with the customers how the company network could create value for them. After revealing the needs, the customer would discuss more about the companies' products with their representatives.

\subsection{Case Project 2}

\section{Business drivers and targeted benefits}

In Case Project 2, two business drivers were identified: desire to support local business growth and customer orientation.

The companies see the local or regional market area as too small to enable them to compete against each other. Thus, foreign customers are seen as necessary. By creating the joint commercial product portfolio, the companies wish to gain the attention of big global customers, not only for the companies' own success but also for the common good of the local area. One interviewee described the ultimate target of cooperation as follows: "to form consortia in which products are bought from several local companies". Conversely, one of the companies that were asked to participate in the effort to create a joint commercial product portfolio refused due to the fear of getting foreign customers.

In addition, the interviewed companies have experienced challenges in finding suitable suppliers and partners. Some have been hoping to buy components or other needed resources from local suppliers and partners but have been unable to find suitable ones due 
to a lack of awareness. Consequently, the companies have signed contracts with foreign suppliers and partners. According to the interviewed companies, the creation of the joint product portfolio could potentially help them to gather knowledge of the local offering and improve overall awareness in the area.

The companies saw potential to join forces by marketing their expertise as a comprehensive concentration of competence to pique the big global customers' interests in the products of the companies operating in the area. This way, they could deliver more value to customers. As each company would have its own part in the whole offering, the companies could focus on their core competences and specialisations without the need to provide a large number of supplementary services by themselves.

\section{Perceived challenges}

The companies were primarily concerned about whether the joint product portfolio serves the purpose after its implementation, and how to manage the cooperation.

The companies were somewhat concerned about whether the constructed joint product portfolio would guide the customer towards the wrong companies in some instances. As the CEO of one company expressed,

If the offerings of the companies would be presented poorly [in too general or misleading a way], the companies might get too many futile enquiries from customers who are looking for something that the company does not provide. This would mean more unnecessary work for us.

Conversely, if the portfolio will be extended to include a large number of companies in the future, it may become overly complicated. One potential challenge also involved consideration of the customer not finding a suitable supplier easily enough, resulting in customer confusion. The confused customer might then try to find a supplier elsewhere. Another concern relates to the currency of the joint portfolio. If the portfolio is not up to date and does not correspond to the companies' actual offerings, the meaning of having the joint portfolio would be lost. If some companies' offerings in the joint portfolio do not correspond to the actual ones, this may make the other companies' efforts somewhat meaningless. 
The question of how the joint product portfolio should be managed as a process is seen as an important consideration, which includes the individual companies' tasks in this process. The interviewees are not sure which kind of governance model should be developed, which includes the companies' responsibilities and roles in the cooperation, nor are they sure what the suitable form of realising the cooperation should be, whether joint sales venture, alliance, or another type. 


\section{DISCUSSION}

This study examines the business drivers and targeted benefits that motivate SMEs to create cooperation through a joint commercial product portfolio. The challenges that companies perceive regarding this type of cooperation are also clarified. This is the first study to examine co-marketing by means of forming a shared commercial product portfolio using product-structure logic.

The results indicate that companies that plan to cooperate through a joint commercial product portfolio are motivated by and concerned about issues that are similar to the benefits and challenges that are found in the other forms of co-marketing. The findings show how SME-sized companies are encouraged to seek cooperation opportunities through a joint commercial product portfolio based on four factors, which are the drivers that characterise their business: need for sales and business growth, customer orientation, drive for cooperation, and desire to support local business.

The need for sales and business growth stems from the studied companies' small sizes and relative newness, as they do not have strong market visibility, a large customer base, or broad marketing and sales channels. Sales are necessary for survival and growth. Cooperation with other companies is seen as an avenue for the growth. A joint commercial product portfolio is seen to improve the possibilities of acquiring a bigger customer base and enhancing company visibility in the market with less resources. A surprising finding, however, entails indications of some SMEs fearing growth if it means obtaining foreign customers.

The companies view the joint commercial product portfolio as an avenue towards a more customer-oriented business. The analysed companies are highly motivated to provide more value to their customers, for which the wider offering created by the joint commercial product portfolio is an avenue. This is realised through the more extensive product offering, which also allows for the development and provision of more specialised products to the customers. Customer value can entail improved communication, improved understanding of customer needs because of cooperation among suppliers, and a combined supplier offering. Therefore, the joint commercial product portfolio is seen as a natural way to carry out the companies' drive for 
cooperation. Complementary $\mathrm{R} \& \mathrm{D}$ and marketing resources, as well as increased resource efficiency, are also seen as benefits of this type of co-marketing.

The desire to support local business growth is identified as a factor motivating cooperation by means of a joint commercial product portfolio. The underlying motivation lies in caring for the local community well-being, increasing awareness of the local offering, and achieving general business success. The findings indicate non-selfish motivations and care for the common good. Certain benevolence can be identified in the motivation to use joint commercial product portfolio as a vehicle to create demand for and awareness of the local companies.

The findings also indicate perceived challenges that relate to cooperation through a joint commercial product portfolio. The challenges that were identified include the perceived risk of entering commercial cooperation by taking one step, as opposed to entering incrementally; potentially different starting points and expectations by the participating companies, as well as the possibility of different interests later becoming a problem for the further development of cooperation; possible opportunistic behaviour by individual companies; lack of resources to invest in cooperation; potential questions over the joint portfolio truly yielding the desired benefits; companies understanding of the value of the joint commercial product portfolio; deficiencies in understanding the products of other participating companies; fear of unnecessary work if the offering is not presented in an ideal way; unwillingness of any single company to take the necessary lead, and the potential need for an external organisation; and, overall, any open questions about managing the cooperation. The recognised challenges relate to managerial and organisational aspects of cooperating through a joint commercial product portfolio, as well as the fear of some risks.

Interestingly, none of the companies were concerned about the possible negative effects that the cooperation could have to their brands, nor did they recognise the weak performance of one partner and how this could possibly weaken the other brands. Another interesting finding is the lack of resources being both a driver of co-marketing to make more out of less and, a barrier to cooperation in the form of concerns over the resources to invest in the cooperation.

\section{Scientific implications}


The study provides new perspectives on the existing co-marketing literature by introducing the creation of a joint commercial product portfolio to serve as a vehicle to support companies' business objectives. The study contributes to the increasing B2B comarketing literature (Bengtsson and Servais, 2005; Morgan et al., 2007; Lavie et al., 2007; Erevelles et al., 2008; Ghosh and John, 2009; Kalafatis et al., 2012; Kalafatis et al., 2014; Törmälä and Saraniemi, 2018; Helm and Özergin, 2015) by presenting the business drivers, targeted benefits and perceived challenges of cooperation through a joint commercial product portfolio by SMEs.

The findings on the need for sales and business growth are in line with those of previous studies (Chen and Huang, 2004; Dacin et al., 2007; Lv et al., 2018) in terms of company size, scarce resources, and deficient market legitimacy being disadvantages that company cooperation might rectify. The findings of this study, however, provide a new contribution by presenting the shared commercial product portfolio as a form of co-marketing to enhance company visibility and credibility. This may, for example, enable the acquisition of more customers by virtually appearing larger. Interestingly, however, there were indications that even if business growth is desired, some factors might override this desire. These included indications that individual companies might fear cooperation if it entails the acquisition of foreign customers. This is in line with the findings of Neupert et al. (2006) that not all companies hope for international operations.

This study provides a new contribution by indicating that regardless of the form of comarketing, the benefits that the companies seek are similar. These findings on this new form of co-marketing - the joint commercial product portfolio - are in line with those of previous research (Rao and Ruekert, 1994; Augustine and Cooper, 2009; Mishra et al., 2017): that the potential co-marketing benefits include increased sales, a larger customer base and markets, and increased market visibility, credibility, number of sales, and marketing channels. The findings are also in line with those of Varadarajan and Cunningham (1995) on the potential of more extensive product offerings as a result of co-marketing. The novelty of this study lies in the introduction of a new type of comarketing. This also supports the logic presented by Brown et al. (2010) that clustered companies potentially get more customer visits due to lower search costs and sourcing from a single location. However, in the case of the joint portfolio, the customer can observe a wider offering with one view. The findings also provide new perspectives for the discussion on single or multiple supplier sources (Costantino and Pellegrino, 2010; 
Segal, 1989; Swift, 1995) by providing one example in the context of a specialised offering in the steel sector.

The findings indicating that cooperation is a source of better business and offers improved access to resources as a benefit of co-marketing efforts are in line with its previously identified benefits (Bucklin and Sengupta, 1993; Rao and Ruekert, 1994; Varadarajan and Cunningham, 1995; Robson and Dunk, 1999; Chen and Huang, 2004). However, the findings on the favouring of local cooperation in co-marketing do not directly support the previously identified geographical proximity (Agostini and Nosella, 2017) as a factor for marketing cooperation, nor the existence of informal social networks as an explanation for it (Felzensztein et al., 2010). Instead, an alternative explanation of a certain drive for common good and certain benevolence towards the local area and its business life is indicated.

This study provides indications that companies are concerned about the same kind of comarketing-related challenges that are presented in the previous literature on other forms of co-marketing. For example, the challenges related to possible risks are in line with the findings on the risks associated with co-marketing success (Day, 1995). Interestingly, the lack of resources acting as a driver for small companies to strive for cooperation (Chen and Huang, 2004), also appears a factor that can act as a barrier to cooperation. The findings, therefore, indicate an interesting dual effect of the lack of resources. They also provide indications that trust plays a role in company cooperation, which is in line with Fink and Kessler (2010), who maintain that time is needed to establish trust.

The challenge of the unclarity over company roles during cooperation via a joint commercial product portfolio may necessitate consideration of a governance model, management process, and rules that include possible penalties for misconduct. The findings do not provide the necessary evidence for this but support the widening of the single-company perspective (Tolonen et al., 2014, 2015) to cover cooperation by multiple companies.

The surprising finding that none of the analysed companies is concerned about the possible negative effects of cooperation on their brands contradicts the previous finding by Rao and Ruekert (1994) and possibly indicates that lack of company visibility in the market drives the desire to build awareness before concern about reputation. The lack of company visibility may also motivate the emphasis on increasing visibility by means of 
co-marketing to gain benefits over concern about the potential unequal distribution of the benefits. This may indicate some variance with previous findings on the distribution of the benefits (Kalafatis et al., 2012; Helm and Özergin, 2015; Karray and Sigué, 2016). Nevertheless, the identified challenge of participating companies having different potential starting points and expectations might imply some concerns regarding inequality.

\section{Managerial implications}

Managers of SMEs can benefit from the results of this study by improving their understanding of co-marketing opportunities through the creation of a joint commercial product portfolio with suitable companies. The participating companies can pursue alternative avenues for increasing sales and market growth by reaching towards scale benefits in marketing while still growing as companies. In addition, company managers can benefit from the insight into the challenges that companies perceive as related to comarketing through a joint commercial product portfolio. This may further support awareness of the challenges related to co-marketing. Managers can consider the presented challenges when planning marketing cooperation.

\section{Limitations and future research}

This study has some limitations. Focusing on specific industries might limit the wider applicability of the findings. Additionally, some interviewees' inability to participate in the second round of interviews might have affected the results. In addition, the limitations include the fact that the study consisted of only two case projects that were based in the same country and, thus, shared a fairly similar business environment and culture. Therefore, the exact same results might not be obtained in a different location, and more research is needed in different business environments. However, regardless of the limited number of cases, a large number of companies took part in the study, making the sample larger than it initially appears. Aside from addressing the limitations, future studies could include companies from different industrial sectors to further validate the findings. Additionally, further clarifying the factors that may override the desire to grow business and increase sales - for example, the fear of acquiring foreign customers - might prove to be an interesting topic for study further. Future research could also focus on developing the process and governance model for the management of the joint commercial product portfolio. 


\section{REFERENCES}

Agostini, L. and Nosella, A. (2017), "Interorganizational Relationships in Marketing: A Critical Review and Research Agenda”, International Journal of Management Reviews, Vol. 19 No. 2, pp. 131-150.

Ahn, S., Kim, H. and Forney, J.A. (2009), "Co-marketing alliances between heterogeneous industries: Examining perceived match-up effects in product, brand and alliance levels", Journal of Retailing and Consumer Services, Vol. 16 No. 6, pp. 477485.

Augustine, M.S. and Cooper, C.D. (2009) "Getting the Most from Strategic Partnering: A Tale of Two Alliances", Organizational Dynamics, Vol. 38 No. 1, pp. 37-51.

Bengtsson, A. and Servais, P. (2005), “Co-branding on industrial markets", Industrial Marketing Management, Vol. 34 No. 7, pp. 706-713.

Brown, P., McNaughton, R.B. and Bell, J. (2010), "Marketing externalities in industrial clusters: A literature review and evidence from the Christchurch, New Zealand electronics cluster", Journal of International Entrepreneurship, Vol. 8 No. 2, pp. 168181.

Bucklin, L.P. and Sengupta, S. (1993), “Organizing Successful Co-Marketing Alliances”, Journal of Marketing, Vol. 57 No. 2, pp. 32-46.

Chen, H.-L. and Huang, Y. (2004), “The Establishment of Global Marketing Strategic Alliances by Small and Medium Enterprises”, Small Business Economics, Vol. 22 No. 5, pp. 365-377.

Costantino, N. and Pellegrino, R. (2010), "Choosing between single and multiple sourcing based on supplier default risk: A real options approach", Journal of Purchasing and Supply Management, Vol. 16 No. 1, pp. 27-40.

Corbin, J. and Morse, J.M. (2003), "The Unstructured Interactive Interview: Issues of Reciprocity and Risks When Dealing With Sensitive Topics", Qualitative Inquiry, Vol. 9 No. 3, pp. 335-354. 
Dacin, M.T., Oliver, C. and Roy, J.-P. (2007), "The legitimacy of strategic alliances: an institutional perspective”, Strategic Management Journal, Vol. 28 No. 2, pp. 169-187.

Das, S., Sen, P.K. and Sengupta, S. (2003), "Strategic alliances: a valuable way to manage intellectual capital?” Journal of Intellectual Capital, Vol. 4 No. 1, pp. 10-19.

Day, G.S. (1995), “Advantageous alliances”, Journal of the Academy of Marketing Science, Vol. 23 No. 4, pp. 297-300.

Duriau, V., Reger, R.K. and Pfaffer, M.D. (2007), “A Content Analysis of the Content Analysis Literature in Organization Studies", Organizational Research Methods, Vol. 10 No. 1, pp. 5-34.

Dyer, J.H. and Singh, H. (1998), “The Relational View: Cooperative Strategy and Sources of Interorganizational Competitive Advantage", The Academy of Management Review, Vol. 23 No. 4, pp. 660-679.

Elo, S. and Kyngäs, H. (2008), "The qualitative content analysis process", Journal of Advanced Nursing, Vol. 62 No. 1, pp. 107-115.

Erevelles, S., Stevenson, T.H., Srinivasan, S. and Fukawa, N. (2008), “An analysis of B2B ingredient co-branding relationships", Industrial Marketing Management, Vol. 37 No. 8, pp. 940-952.

Felzensztein, C., Gimmon, E. and Carter, S. (2010), “Geographical Co-Location, Social Networks and Inter-firm Marketing Co-operation: the Case of the Salmon Industry”, Long Range Planning, Vol. 43 No. 5-6, pp. 675-690.

Felzensztein, C., Gimmon, E. and Aqueveque, C. (2012), "Clusters or un-clustered industries? Where inter-firm marketing cooperation matters", Journal of Business \& Industrial Marketing, Vol. 27 No. 5, pp. 392-402.

Ferdinand, A.T. and Killa, M.F. (2018), "The Pareto Sales Network Asset: A Networked Power Perspective”, Business: Theory and Practice, Vol. 19, pp. 114-124. 
Fink, M. and Kessler, A. (2010), “Cooperation, Trust and Performance - Empirical Results from Three Countries", British Journal of Management, Vol. 21, No.2, pp.469483.

Gammoh, B.S. and Voss, K.E. (2013), “Alliance competence: The moderating role of valence of alliance experience", European Journal of Marketing, Vol. 47 No. 5/6, pp. 964-986.

Gammoh, B.S., Voss, K.E. and Chakrabory, G. (2006), “Consumer Evaluation of Brand Alliance Signals”, Psychology and Marketing, Vol. 23 No. 6, pp. 465-486.

Gammoh, B.S., Voss, K.E. and Fang, X. (2010), "Multiple brand alliances: a portfolio diversification perspective", Journal of Product \& Brand Management, Vol. 19 No. 1, pp. 27-33.

Ghosh, M. and John, G. (2009), "When Should Original Equipment Manufacturers Use Branded Component Contracts with Suppliers?” Journal of Marketing Research, Vol. 46 No. 5, pp. 597-611.

Gilmore, A., Carson, D. and Grant, K. (2001), "SME marketing in practice”, Marketing Intelligence \& Planning, Vol. 19 No. 1, pp. 6-11.

Gou,Q., Zhang, J., Liang, L., Huang, Z. and Ashley, A. (2014), "Horizontal cooperative programmes and cooperative advertising”, International Journal of Production Research, Vol. 52 No. 3, pp. 691-712.

Grieco, C. and Iasevoli, G. (2017), "Co-marketing alliances: definitions and approaches. Insights from a literature review”, Management Research Review, Vol. 40 No. 9, pp. 971989.

Harkonen, J., Tolonen, A. and Haapasalo, H. (2017), "Service productisation: systematising and defining an offering", Journal of Service Management, Vol. 28 No. 5, pp. 936-971. 
Helm, S.V. and Özergin, B. (2015), "Service inside: The impact of ingredient service branding on quality perceptions and behavioral intentions", Industrial Marketing Management, Vol. 50, pp. 142-149.

Kalafatis, S.P., Remizova, N., Riley, D. and Singh, J. (2012), "The differential impact of brand equity on B2B branding", Journal of Business \& Industrial Marketing, Vol. 27 No. 8, pp. 623-634.

Kalafatis, S.P., Riley, D. and Singh, J. (2014), "Context effects in the evaluation of business-to-business brand alliances”, Industrial Marketing Management, Vol. 43 No. 2, pp. 322-334.

Karray, S. and Sigué, S.P. (2015), “A game-theoretic model for co-promotions: Choosing a complementary versus an independent product ally”, Omega, Vol. 54, pp. 84-100.

Karray, S. and Sigué, S.P. (2016), "Should companies jointly promote their complementary products when they compete in other product categories?" European Journal of Operational Research, Vol. 255 No. 2, pp. 620-630.

Lavie, D., Lechner, C. and Singh, H. (2007), "The performance implications of timing of entry and involvement in multipartner alliances", Academy of Management Journal, Vol. 50 No. 3, pp. 578-604.

Levin, A.M., Davis, J.C. and Levin, I. (1996), "Theoretical and Empirical Linkages Between Consumers' Responses to Different Branding Strategies”, Advances in Consumer Research, Vol. 23 No. 1, pp. 296-300.

Lv, D.D., Zeng, P. and Lan, H. (2018), “Co-patent, financing constraints, and innovation in SMEs: An empirical analysis using market value panel data of listed firms", Journal of Engineering and Technology Management, Vol. 48, pp. 15-27.

Mäläskä, M., Saraniemi, S. and Tähtinen, J. (2011), "Network actors’ participation in B2B SME branding”, Industrial Marketing Management, Vol. 40 No. 7, pp. 1144-1152. 
Mishra, S. and Singh, S.N. (2017), "Impact of diversity, quality and number of brand alliance partners on the perceived quality of a new brand", Journal of Product \& Brand management, Vol. 35 No. 2, pp. 166-179.

Mohan, M., Brown, B.P., Sichtmann, C. and Schoefer, K. (2018), "Perceived globalness and localness in B2B brands: A co-branding perspective", Industrial Marketing Management, Vol. 72, pp. 59-70.

Morgan, F., Deeter-Schmelz, D. and Moberg, C.R. (2007), "Branding implications of partner firm-focal firm relationships in business-to-business service networks", Journal of Business \& Industrial Marketing, Vol. 22 No. 6, pp. 372-382.

Neupert, K.E., Baughn, C.C. and Dao, T.T.L. (2006), "SME exporting challenges in transitional and developed economies", Journal of Small Business and Enterprise Development, Vol. 13 No. 4, pp. 535-545.

Park, C.W., Jun, S.Y. and Shocker, A.D. (1996), "Composite Branding Alliances: An Investigation of Extension and Feedback Effects", Journal of Marketing Research, Vol. 33 No. 4, pp. 453-466.

Rao, A.R. and Ruekert, R.W. (1994), "Brand Alliances as Signals of Product Quality”, Sloan Management Review, Vol. 36 No. 1, pp. 87-97.

Ratajczak-Mrozek, M., Fonfara, K. and Hauke-Lopes, A. (2019), “Conflict handling in small firms' foreign business relationships", Journal of Business \& Industrial Marketing, Vol. 34 No. 1, pp. 240-252.

Rich, M.K. (2003), "Requirements for successful marketing alliances", Journal of Business \& Industrial Marketing, Vol. 18 No. 4/5, pp. 447-456.

Robson, M.J. and Dunk, M.A.J. (1999), “Case study: Developing a pan-European comarketing alliance: the case of BP-Mobil", International Marketing Review, Vol. 16 No. 3, pp. 216-230.

Segal, M.N. (1989), "Implications of single vs. multiple buying sources". Industrial Marketing Management, Vol. 18 No. 3, pp.163-178. 
Sengupta, S. (1998), "Some Approaches to Complementary Product Strategy”, Journal of Product Innovation Management, Vol. 15 No. 4, pp. 352-367.

Swift, C.O. (1995), "Preferences for single sourcing and supplier selection criteria", Journal of Business Research, Vol. 32 No. 2, pp.105-111.

Teng, B.-S. and Das, T.K. (2008), "Governance structure choice in strategic alliances: The roles of alliance objectives, alliance management experience, and international partners", Management Decision, Vol. 46 No. 5, pp. 725-742.

Tolonen, A., Harkonen, J. and Haapasalo, H. (2014), "Product Portfolio Management Governance For Commercial and Technical Portfolios Over Life Cycle”, Technology and Investment, Vol. 5 No. 4, pp. 173-183.

Tolonen, A., Harkonen, J., Verkasalo, M. and Haapasalo, H. (2015), "Product portfolio management process over horizontal and vertical portfolios", International Journal of Product Lifecycle Management, Vol. 8 No. 3, pp. 189-215.

Törmälä, M. and Saraniemi, S. (2018), “The roles of business partners in corporate brand image co-creation", Journal of Product \& Brand Management, Vol. 27 No. 1, pp. 29-40.

Varadarajan, P.R. and Cunningham, M.G. (1995), "Strategic Alliances: A Synthesis of Conceptual Foundations", Journal of the Academy of Marketing Science, Vol. 23, pp. 282-296.

Venkatesh, R. and Mahajan, V. (1997), "Products with Branded Components: An Approach for Premium Pricing and Partner Selection”, Marketing Science, Vol. 16 No. 2, pp. 146-165.

Voss, K.E. and Gammoh, B.S. (2004), "Building Brands through Brand Alliances: Does a Second Ally Help?” Marketing Letters, Vol. 15 No. 2-3, pp. 147-159.

Voss, K.E., Johnson, J.L., Cullen, J.B., Sakano, T. and Takenouchi, H. (2006), "Relational exchange in US-Japanese marketing strategic alliances", International Marketing Review, Vol. 23 No. 6, pp. 610-635. 
Voss, K.E. and Tansuhaj, P. (1999), “A Consumer Perspective on Foreign Market Entry”, Journal of International Consumer Marketing, Vol. 11 No. 2, pp. 39-58.

Yi, H.T., Lee, J. and Dubinsky, A.J. (2010), “An Empirical Investigation of Relational Conflicts in Co-Marketing Alliances”, Journal of Business-to-Business Marketing, Vol. 17 No. 3, pp. 249-278.

Zhang, Y. and Wildemuth, B.M. (2017), "Unstructured Interviews", in Wildemuth, B.M. (Ed.), Applications of Social Research Methods to Questions in Information and Library Science, $2^{\text {nd }}$ ed., Libraries Unlimited, Santa Barbara, CA, pp. 239-247. 